\title{
Cell-free circulating tumor DNA mutation profiling for cervical carcinoma as diagnostic biomarker: A 50-genes module to future directive
}

\author{
Govardhan HB ${ }^{1}$, Khaleel IA ${ }^{1}$, Shubha SA $^{1}$, Manisha $\mathbf{R}^{1}$, Nivedita $\mathbf{S}^{1}$, Noopur $\mathbf{N}^{1}$, \\ Jayashree NP ${ }^{1}$, Fareena $\mathrm{T}^{1}$ and Sweta $\mathrm{K}^{1}$ \\ ${ }^{1}$ Department of Radiation Oncology, Kidwai Cancer Institute, Bangalore, Karnataka, India \\ Correspondence to: Govardhan HB, email: govardhanhb@gmail.com
}

Keywords: cervical carcinoma; cfTDNA; next generation sequencing; minimally-invasive; biomarker

Received: November 08, $2018 \quad$ Accepted: January 04, $2019 \quad$ Published: January 13, 2019

Copyright: GovardhanHB et al. This is an open-access article distributed under the terms of the Creative Commons Attribution License 3.0 (CC BY 3.0), which permits unrestricted use, distribution, and reproduction in any medium, provided the original author and source are credited.

\section{ABSTRACT}

Introduction: Currently, tissue biopsy is the gold-standard to verify carcinoma of uterine cervix initial diagnosis and can be challenging due to its invasive nature. In this study, our objective was a non-invasive genetic panel for timely detection of cervical carcinoma and its progression using cell-free tumour DNA (cfTDNA).

Materials and Methods: 25 cervical carcinoma patients were tested with a 50gene tumour panel. cfTDNA isolated from serum was checked for single nucleotide variations (SNVs) or copy number alterations (CNAs) using targeted Next Generation Sequencing (NGS), with further validation of results by checking respective formalinfixed paraffin-embedded (FFPE) tumor tissues for the same genetic alterations.

Results: 32/50 genes were detected in the serum samples. The SNVs detected included TP53 in 52.3\% patients, CDKN2A in 47.6\%, PTEN and STK11 in 33.3\% patients, BRAF and VHL in $28.5 \%$ patients, EGFR and SMAD4 in 19\% patients; CTNNB1, GNAS, KIT, APC, PIK3CA in 14.28\% patients; SMARCB1, SMO, RET, FBXW7, ERBB2, CSF1R, CDH1, AKT1, ATM, EBB4, FGFR3, FLT3, HRAS, JAK3, MET, NOTCH1, NPM1, KRAS, PTPN11 in 4.7 to $9.5 \%$ patients.

Conclusions: These findings illustrate that cfTDNA is easily demonstrable and can be used as a surrogate for tissue biopsy in uterine cervix carcinoma.

\section{INTRODUCTION}

Cervical carcinoma $(\mathrm{CC})$ being one of the principal causes of death among women, especially those in the prime of their reproductive lives, poses as a major health threat for the women spectrum worldwide. Globally, in 2012 alone, an estimated 528,000 instances of cervical cancer were recorded, of which around $85 \%$ of the cases occurred in low- and middle-income countries. Around 266,000 females died of cervical cancer, accounting for $7.5 \%$ of all female cancer causalities [1]. Hence, the development of suitable techniques for early and prompt detection of CC, portrays a mammoth medical challenge for individuals and health institutions alike, potentially focusing research efforts in these areas. Inspired to contribute to global medical communities' efforts, our team suggests the use of blood-based diagnosis to detect CC.

Although tumor tissue is still the yardstick for tumour diagnosis and evaluation, chief disadvantages are engrossed in obtaining tissue samples (i.e., biopsies may be complicated and are invasive procedures). Furthermore, a tissue biopsy is often obtained from only one tumor site, and the genetics of distant metastases cannot be determined [2], [3]. Despite its inconveniences, tumor biopsy remains the most dynamic diagnostic tool at present.

Human serum is acknowledged to bear minuscule extent of extracellular tumour-derived fragmented and 160-180 bp long DNA molecules named cell-free Tumour DNA (cfTDNA) [4], [5]. These are likely to originate from necrotic and apoptotic cells into the circulation [6]. 
In cancer patients, cfTDNA may harbor somatically derived tumor-specific mutations displaying the genomic description of an individual's cancer, for instance, single nucleotide variants or structural rearrangements [7]. cfTDNA is therefore deemed as a genomic reservoir of different tumor clones and a good illustration of tumor genomic diversity when weighed against a single tumor sample. This inducts cfTDNA a quintessential candidate for the base of a blood-based cancer diagnosis test [8].

Nevertheless, several key advantages of cfTDNA justify further investigation and development as a tool to detect tumor-specific genomic alterations in the circulation, beyond what is currently possible with tumor biopsy. First, the likelihood of cfTDNA analysis even with low levels of cfDNA may result in early detection of cancer. Second, even when biopsy is technically viable, the nominally invasive, more appropriate cfTDNA quantification would be more adequate to patients than biopsy. Third, cfTDNA analysis facilitates monitoring of molecular alterations accompanying tumor response or acquired resistance, while sparing the patient from repeated biopsies and their probable harms.

As genetic alterations that require to be identified from cfTDNA are diluted by non-tumoral cell-free DNA and non-mutated cell-free DNA, highly sensitive and specific detection methods are needed to provide a relatable cfTDNA-based diagnosis. This concern has directed towards improvement and development of plentiful methods to investigate tumor-specific mutations in cfTDNA, for instance, "BEAMing" (Beads, Emulsions, Amplification and Magnetics) allele-specific PCR and droplet digital PCR (ddPCR) [9], [10], [11]. Although these techniques are highly sensitive, a low throughput on mutation scanning and the requisite of predefined knowledge of molecular targets to test for, are their major drawbacks. Compared to the polymerase chain reaction (PCR)-based detection mode, which scans for defined mutations at a specific genomic locus, next generation sequencing (NGS)-based techniques allows for profiling of cfTDNA at a broader range [12], [13]. NGS puts forward unprecedented progress in revealing cancer genome characteristics and aiding personalized cancer therapy as a result of its exceptional precision, sensitivity, and high throughput.

The purpose of this study was to investigate the diagnostic and prognostic significance of somatic mutations in cfTDNA, to be used as an authenticate substitute for tissue biopsies in patients with CC. Moreover, here we are also presenting an NGS workflow using a 50-gene sequencing panel applied to a cohort of $\mathrm{CC}$ patients to detect tumor-specific mutations in only minute amounts of serum-derived cfTDNA.

\section{RESULTS}

We report data from twenty-five patients with squamous cervix carcinoma prospectively enrolled in the study. Table 2 details the patient characteristics of the study population are summarized in. The source of archival tissue sample was the formalin-fixed paraffinembedded (FFPE) blocks.

\section{PATIENTS DETECTED WITH CFTDNA}

Firstly, we evaluate the patients detected with cfTDNA. Overall, we detected genetic alterations in genes of $21(84 \%)$ patients' cfTDNA out of 25 . The mean genetic alteration was 4.08 (2-14). In 4/21 (19\%) patients, more than eight genomic alterations were detected, another $4 / 21$ (19\%) patients had 5-7 genetic alteration, remaining 13/21 $(61.9 \%)$ patients showed less than four genetic alterations (Figure 1).

\section{Single nucleotide variations (SNVs) detected}

Out of 50 genes, 32 genes were detected in our patients. As shown in Table 3 most common SNVs detected were TP53-11/21 (52.3\%) patients, CDKN2A-10/21 (47.6\%) patients, PIK3CA-9/21 (42.8\%) patients, PTEN and STK11-7/21 (33.3\%) patients, BRAF and $V H L-6 / 21$ (28.5\%) patients, EGFR and SMAD4-4/21 (19\%) patients, CTNNB1, GNAS, KIT, APC, PIK3CA-3/21 (14.28\%) patients, SMARCB1, SMO, RET, FBXW7, ERBB2, CSF1R, CDH1, AKT1, ATM, EBB4, FGFR3, FLT3, HRAS, JAK3, MET, NOTCH1, NPM1, KRAS, PTPN11-1 or $2 / 21(4.7$ to $9.5 \%)$ patients.

On combination of the aforementioned genetic alterations- $B R A F, \quad C D K N 2 A, \quad E G F R \quad P I K 3 C A$, $P T E N$, STK11, TP53, and VHL genes had the main

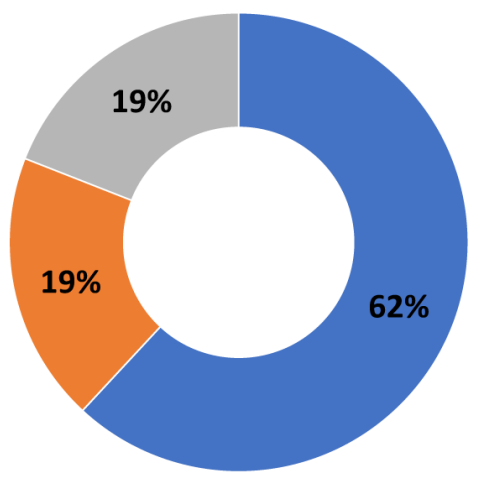

$$
\text { Number of mutations in patients }
$$$$
\square \leq 4 \square \text { to } 7 \square 8<
$$

Figure 1: Percentage of patients that were positive for genetic mutations $(n=21)$. 
Table 1: List of 50 genes in the diagnostic panel

\begin{tabular}{|l|l|l|l|l|}
\hline ABL1 & EGFR & GNAS & MPL & PIK3CA \\
\hline AKT1 & ERBB2 & GNAQ & NOTCH1 & RB1 \\
\hline ALK & ERBB4 & HNF1A & NPM1 & RET \\
\hline APC & EZH2 & HRAS & NRAS & SMAD4 \\
\hline ATM & FGFR1 & IDH1 & KRAS & SMO \\
\hline BRAF & FBXW7 & IDH2 & KDR & SMARCB1 \\
\hline CDH1 & FGFR2 & JAK2 & KIT & SRC \\
\hline CDKN2A & FGFR3 & JAK3 & PTEN & STK11 \\
\hline CSF1R & FLT3 & MLH1 & PTPN11 & TP53 \\
\hline CTNNB1 & GNA11 & MET & PDGFRA & VHL \\
\hline
\end{tabular}

alterations and on combination of these genes, at least one genetic alteration among combination was found in $100 \%$ patients at any point of time as summarized in Figure 2. Thus, this gene panel can be used as a diagnostic genetic module.

In our study, we found that with an increase in the stage, the number of genes expressed amplified (Table 4). Further, patients' survival data was collected for 36 months from hospital files and by phone calls. It was found that among patients with genetic alterations, 12 were alive (all completed treatment) and 9 were dead (cancer-related) (7 completed treatment). Survival ranged from 2 to 28 months with a median survival of 19 months. It was found that most of the deaths occurred in advance stage (IIB-IIIB).

Another important finding was that patients with changes in APC; ATM; BRAF; CDKN2A; CSF1R; EGFR; FLT3; HRAS; JAK3; KIT; PTEN; PTPN11; STK11; TP53 and $V H L$ genes were found to have a more aggressive disease than those minus the abovementioned (Table 5).

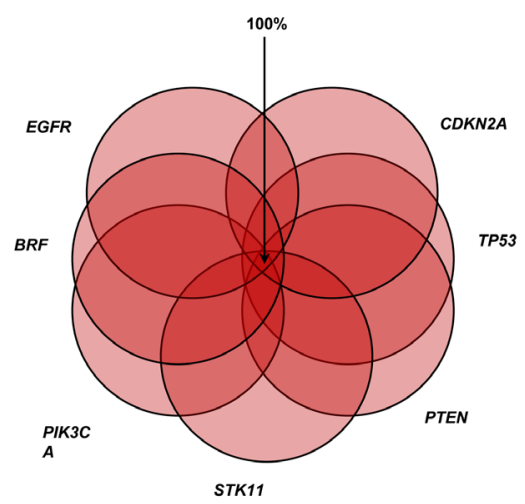

Figure 2: Combination of genetic alterations in $B R A F$, CDKN2A, EGFR, PIK3CA, STK11, TP53 and VHL genes.
Table 2: Patient, tumour and histopathological characteristics at the time of sampling

\begin{tabular}{|l|l|}
\hline \multicolumn{2}{|l|}{ PATIENT CHARACTERISTICS } \\
\hline Total number of patients $(\boldsymbol{n})$ & 25 \\
\hline Age (years) & $\begin{array}{l}\text { Mean=51.57 } \\
\text { Range }=30-83\end{array}$ \\
\hline FIGO Tumour Stage & $\begin{array}{l}\text { Number of patients } \\
n(\%) \\
\text { IB } \\
\text { IIA }\end{array}$ \\
IIB & $\begin{array}{l}2(8 \%) \\
3(12 \%) \\
\text { IIIA }\end{array}$ \\
IIIB & $\begin{array}{l}12(48 \%) \\
7(28 \%)\end{array}$ \\
\hline Histopathology Squamous cell \\
carcinoma & $25(100 \%)$ \\
\hline HPV Status & $21(84 \%)$ \\
\hline Patients' status at the 3rd year of the study \\
\hline Status & $\begin{array}{l}\text { No of patients } \\
(n=21)\end{array}$ \\
\hline Alive & 12 \\
\hline Death & 9 \\
\hline
\end{tabular}

\section{DISCUSSION}

In the present study, we have devised a module consisting of 50-malignancy associated genes with a perspective of designing a minimally invasive diagnostic and prognostic tool for CC patients. Provided the method to detect somatic mutations in serum cfTDNA, targeted sequencing by NGS has already displayed its efficacy in clinical practice and translational research for several solid tumors or lymphoma [14], [15].

In our analysis, out of twenty-five patients, twentyone were detected with genomic alterations in cfTDNA by sequencing with the targeted panel. Of these patients, four individuals had more than eight genomic alterations, another four patients had 5-7 genetic alteration and remaining thirteen patients harboured less than four genetic alterations in cfTDNA. Out of 50 genes, 32 genes were detected in our patients. As shown in Table 3 most common SNVs detected were TP53-11/21 (52.3\%) patients, $C D K N 2 A-10 / 21$ (47.6\%) patients, $P I K 3 C A-9 / 21$ (42.8\%) patients, PTEN and STK11-7/21 (33.3\%) patients, $B R A F$ and $V H L-6 / 21$ (28.5\%) patients, EGFR and SMAD4-4/21 (19\%) patients, CTNNB1, GNAS, KIT, $A P C, P I K 3 C A-3 / 21$ (14.28\%) patients, SMARCB1, SMO, RET, FBXW7, ERBB2, CSF1R, CDH1, AKT1, ATM, EBB4, FGFR3, FLT3, HRAS, JAK3, MET, NOTCH1, NPM1, KRAS, PTPN11-1or2/21 (4.7 to 9.5\%) patients. This data depicts that TP53 coding for p53 is the common mutation occurring in cervical cancer patients followed by mutations in $C D K N 2 A$ and $P I K 3 C A$ as summarized in 
Table 3: Individual genetic alteration frequency in patients

\begin{tabular}{|c|c|}
\hline Individual genetic alterations-SNV & $(n=21)$ \\
\hline TP53 & $11(52.3 \%)$ \\
\hline$C D K N 2 A$ & $10(47.6 \%)$ \\
\hline PIK3CA & $9(42.8 \%)$ \\
\hline PTEN,STK-11 & $7(33.3 \%)$ \\
\hline$B R A F, V H L$ & $6(28.5 \%)$ \\
\hline EGFR,SMAD4 & $4(19 \%)$ \\
\hline$C T N N B 1, G N A S, K I T, A P C$ & $3(14.28 \%)$ \\
\hline $\begin{array}{l}\text { SMARCB1, SMO, RET, FBXW7,ERBB2, } \\
\text { CSF1R, AKT1,ATM, CDH1, ERBB4, } \\
\text { FGFR3, FGFR3, FLT3,HRAS, } \\
\text { JAK3,MET, NOTCH1,NPM1, KRAS, } \\
\text { PTPN11 }\end{array}$ & 1 to $2(4.7$ to $9.5 \%)$ \\
\hline
\end{tabular}

Table 4: Genes association with patients' status

\begin{tabular}{|c|c|}
\hline $\begin{array}{l}\text { Genes associated with live } \\
\text { patients (good prognostic } \\
\text { genes) }\end{array}$ & \begin{tabular}{|lr} 
Genes & associated \\
with dead patients \\
(bad & prognostic \\
genes) & \\
\end{tabular} \\
\hline $\begin{array}{l}C T N N B 1 ; E R B B 4 ; F B X W 7 ; \\
F G F R 3 ; \text { KRAS; NOTCH1; } \\
\text { NPM1; and SMO }\end{array}$ & $\begin{array}{l}\text { APC; ATM; BRAF; } \\
\text { CDKN2A; CSF1R; } \\
\text { EGFR; FLT3; HRAS; } \\
\text { JAK3; KIT; PTEN; } \\
\text { PTPN11; STK11; } \\
\text { TP53 and VHL }\end{array}$ \\
\hline
\end{tabular}

Figure 3.

On merging the abovementioned genetic alterationsBRAF, CDKN2A, EGFR PIK3CA, PTEN, STK11, TP53, and $V H L$ genes had the main alterations and on grouping of these genes, at least one genetic alteration among combination was found in $100 \%$ patients at any point of time. Thus, we conclude that this gene panel can be used as a diagnostic genetic module.

The detection rate $(21 / 25,84 \%)$ was similar to another study that included patients suffering from secondary brain tumors: $24 / 27(88.8 \%)$ in a cohort of highgrade glioma patients. Among our genetic module STK11 (55.5\%), TP53 (44.4\%), PTEN (44.4\%), and VHL (33.3\%) are associated with bad prognosis i.e., death/progression of disease. VHL is the most specific gene and STK11 is the most frequent bad prognostic gene.

Also, we found that with increase in stage, the number of genes expressed increased (Table 4). This analysis substantiates the liquid biopsy concept, as a minimally-invasive diagnostic test. Furthermore, NGS may be used as a molecular diagnostic method ahead of delivering targeted therapies allowing for detection of specific alteration in a targeted manner.
Table 5: Inter-relation of genes, carcinoma stage, death/life of patients

\begin{tabular}{|c|c|c|c|}
\hline Stage & Genes & \begin{tabular}{ll|} 
No. & of \\
Genes & \\
\end{tabular} & Deaths \\
\hline $\operatorname{IB}(n=2)$ & SMO, TP53 & 2 & 0 \\
\hline $\operatorname{IIA}(n=1)$ & $C D K N 2 A, P I K 3 C A$ & 2 & 0 \\
\hline $\operatorname{IIB}(n=10)$ & $\begin{array}{lr}A P C, & A T M, \\
C D K N 2 A, & C S F I R, \\
\text { EGFR, } & \text { ERBB2, } \\
\text { ERBB4, } & \text { FBXW7, } \\
\text { FGFR3, } & \text { GNAS, } \\
\text { NOTCH, } & \text { PIK3CA, } \\
\text { RET, SMAD4, SMO, } & \text { SM } \\
\text { TP53, } & \text { SMARCB1, } \\
\text { STK11 } & \\
\end{array}$ & $1-14$ & 5 \\
\hline $\operatorname{IIIA}(n=1)$ & $\begin{array}{ll}\text { EGFR, } & \text { PTEN, } \\
\text { SMAD4, } & \text { STK11, } \\
\text { TP53, VHL } & \\
\end{array}$ & 6 & 1 \\
\hline $\operatorname{IIIB}(n=7)$ & $\begin{array}{lr}A K T, & B R A F, \\
C D H 1, & C D K N 2 A, \\
E G F R, & F B X W 7, \\
F L T 3, & G N A S, \\
J A K 3, & P T E N, \\
K I T, & P I K 3 C A, \\
R E T, & S M A D 4, \\
\text { SMARCB1, STK11, } & \text { STA VHL } \\
\text { Tp53, VHL }\end{array}$ & $2-13$ & 3 \\
\hline
\end{tabular}

\section{MATERIALS AND METHODS}

\section{Study population}

A total of twenty-five patients $(n=25)$ with histopathologically confirmed locally advanced squamous cell carcinoma of the cervix (FIGO Stage IB-IIIB) were enrolled prospectively in the study. Written consent was obtained from each patient to allow the use of their

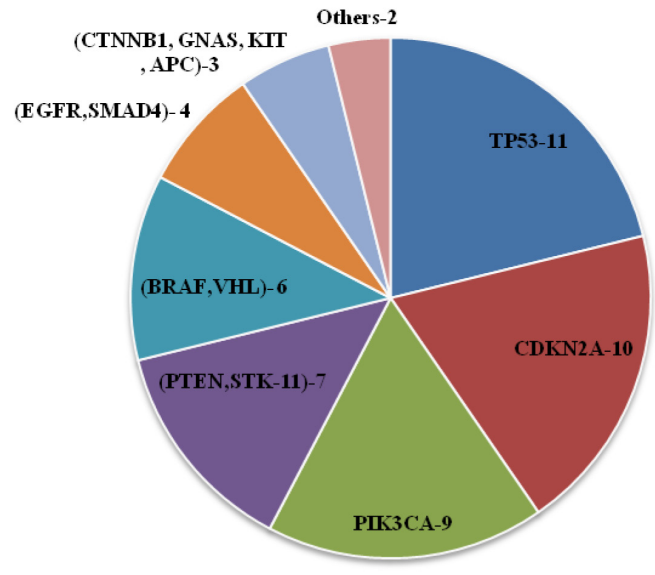

Figure 3: Genes that are frequently mutated in cervical cancer. 
samples for scientific research. The mean age of the complete series was 51.57 years (Range: 30-83years). In all the cases a biopsy of respective (FFPE) tumour tissue was available. Demographical, clinicopathological features (stage, grade), courses of treatment(s), and vital status were acquired from the clinical and pathology reports. All the patients underwent external beam radiation therapy (EBRT) followed by internal beam radiation therapy (IBRT) according to the institutional protocol and were on regular follow-up for upto 36 months with their survival and local control being assessed consistently. In our study, it ranged from two to twenty-eight months with a median survival of 19 months.

\section{Laboratory analysis}

\section{Sample collection $\&$ dna extraction}

Twenty-five venous blood samples were collected from the patients into blood collection Tube with $\mathrm{K}_{3}$ EDTAand $4 \mathrm{ml}$ of serum was obtained by centrifugation within three hours after blood extraction at 2500rpm at $37^{\circ} \mathrm{C}$. cfTDNA was extracted from the serum by circulating nucleic acid kit, as per standard procedure. Besides, the samples were also analyzed for human papilloma virus (HPV).

\section{Targeted ngs-based gene mutation profiling}

We designed a 50-gene panel based on our previous studies and publicly available databases. The cfTDNA detected in the serum samples was sufficient to carry out NGS. Genes carrying specific somatic mutations like single nucleotide variations (SNVs)/copy number alterations (CNAs) were screened by NGS using this panel.

\section{To screen somatic mutations in tumor tissue}

For the analyses of FFPE tumor samples DNA was purified from four 5.0-mm-thick unstained FFPE sections according to the standard DNA FFPE tissue protocol and the gene mutations were screened by NGS targeting 50 cancer genes (Table 1). To rule out the germ line mutations and to correlate with cfTDNA relevant statistical test were exercised.

\section{Statistical analysis}

Statistical analysis was performed using SPSS version 18.0 (SPSS Inc., Chicago, IL, USA). The correlation among the quantitative variables was evaluated with simple linear regression analysis. The chi-square test was used and (Pearson chi-square; $P<0.005$ ) was considered to be statistically significant difference.

\section{Abbreviations}

CC: Cervical carcinoma; cfTDNA: cell free Tumour DNA; BEAMing: Beads, Emulsions, Amplification and Magnetics; ddPCR: droplet digital PCR; PCR: polymerase chain reaction; NGS: next generation sequencing; FFPE: formalin-fixed paraffin-embedded; SNVs: Single nucleotide variations; CNAs: copy number alterations; HPV: human papilloma virus

\section{Author contributions}

We acknowledge the contributions by Govardhan $\mathrm{HB}$ and Khaleel IA who conceived and designed the study protocol; Shubha S A who was responsible for acquisition of data and Manisha $\mathrm{R}$ for autonomously writing reviewing and/or revision of the manuscript; Nivedita $\mathrm{S}$ and Noopur $\mathrm{N}$ who provided technical support and study supervision; Jayashree NP, Fareena T, and Sweta K who gave help during the course of the study.

\section{ACKNOWLEDGMENTS}

We would like to duly acknowledge the patients for providing their samples and also to the data entry operator for timely and regular support to thus study.

\section{CONFLICTS OF INTEREST}

The authors declare no conflict of interest.

\section{FUNDING}

The study received no funding.

\section{REFERENCES}

1. Ferlay J, Soerjomataram I, Dikshit R, Eser S, Mathers C, Rebelo M, Parkin DM, Forman D, Bray F. Cancer incidence and mortality worldwide: Sources, methods and major patterns in GLOBOCAN 2012. Int J Cancer. 2015; 136:E359-E386. https://doi.org/10.1002/ijc.29210.

2. Chan KC, Jiang P, Zheng YW, Liao GJ, Sun H, Wong J, Siu SS, Chan WC, Chan SL, Chan AT, Lai PB, Chiu RW, Lo $\mathrm{YM}$, et al. Cancer genome scanning in plasma: Detection of tumor-associated copy number aberrations, singlenucleotide variants, and tumoral heterogeneity by massively parallel sequencing. Clin Chem. 2013; 59:211-224. https:// doi.org/10.1373/clinchem.2012.196014.

3. Heitzer E, Ulz P, Belic J, Gutschi S, Quehenberger F, Fischereder K, Benezeder T, Auer M, Pischler C, Mannweiler S, Pichler M, Eisner F, Haeusler M, Riethdorf $\mathrm{S}$, et al. Tumor-associated copy number changes in the circulation of patients with prostate cancer identified 
through whole-genome sequencing, Genome Med. 2013; 5:30. https://doi.org/10.1186/gm434.

4. Anker P, Mulcahy H, Chen XQ, Stroun M. Detection of circulating tumour DNA in the blood (plasma/serum) of cancer patients. Cancer Metastasis Rev. 1999; 18:65-73. http://www.ncbi.nlm.nih.gov/pubmed/10505546.

5. Lo YM, Zhang J, Leung TN, Lau TK, Chang AM, Hjelm NM. Rapid clearance of fetal DNA from maternal plasma. Am J Hum Genet. 1999; 64:218-24. https://doi. org/10.1086/302205.

6. De Mattos-Arruda L, Caldas C. Cell-free circulating tumour DNA as a liquid biopsy in breast cancer. Mol Oncol. 2016; 10:464-74. https://doi.org/10.1016/j.molonc.2015.12.001.

7. Murtaza M, Dawson SJ, Tsui DWY, Gale D, Forshew T, Piskorz AM, Parkinson C, Chin SF, Kingsbury Z, Wong ASC, Marass F, Humphray S, Hadfield J, et al. Noninvasive analysis of acquired resistance to cancer therapy by sequencing of plasma DNA. Nature. 2013; 497:108-112. https://doi.org/10.1038/nature12065.

8. Warton K, Mahon KL, Samimi G. Methylated circulating tumor DNA in blood: power in cancer prognosis and response. Endocr Relat Cancer. 2016; 23:R157-71. https:// doi.org/10.1530/ERC-15-0369.

9. Diehl F, Schmidt K, Choti MA, Romans K, Goodman S, Li M, Thornton K, Agrawal N, Sokoll L, Szabo SA, Kinzler KW, Vogelstein B, Diaz LA Jr. Circulating mutant DNA to assess tumor dynamics. Nat Med. 2008; 14:985-990. https:// doi.org/10.1038/nm.1789.

10. Thierry AR, Mouliere F, El Messaoudi S, Mollevi C, Lopez-Crapez E, Rolet F, Gillet B, Gongora C, Dechelotte P, Robert B, Del Rio M, Lamy PJ, Bibeau F, et al. Clinical validation of the detection of KRAS and BRAF mutations from circulating tumor DNA. Nat Med. 2014; 20:430-435. https://doi.org/10.1038/nm.3511.

11. Freidin MB, Freydina DV, Leung M, Montero Fernandez A, Nicholson AG, Lim E. Circulating tumor DNA outperforms circulating tumor cells for KRAS mutation detection in thoracic malignancies. Clin Chem. 2015; 61:1299-1304. https://doi.org/10.1373/clinchem.2015.242453.

12. Forshew T, Murtaza M, Parkinson C, Gale D, Tsui DWY, Kaper F, Dawson SJ, Piskorz AM, Jimenez-Linan M, Bentley D, Hadfield J, May AP, Caldas C, et al. Noninvasive identification and monitoring of cancer mutations by targeted deep sequencing of plasma DNA. Sci Transl Med. 2012; 4:136ra68-136ra68. https://doi.org/10.1126/ scitranslmed.3003726.

13. Newman AM, Bratman SV, To J, Wynne JF, Eclov NCW, Modlin LA, Liu CL, Neal JW, Wakelee HA, Merritt RE, Shrager JB, Loo BW, Alizadeh AA, et al. An ultrasensitive method for quantitating circulating tumor DNA with broad patient coverage. Nat Med. 2014; 20:548-554. https://doi. org/10.1038/nm.3519.

14. Schwaederle M, Husain H, Fanta PT, Piccioni DE, Kesari S, Schwab RB, Banks KC, Lanman RB, Talasaz A, Parker BA, Kurzrock R. Detection rate of actionable mutations in diverse cancers using a biopsy-free (blood) circulating tumor cell DNA assay. Oncotarget. 2016; 7:9707-17. https:// doi.org/10.18632/oncotarget.7110.

15. Frenel JS, Carreira S, Goodall J, Roda D, Perez-Lopez R, Tunariu N, Riisnaes R, Miranda S, Figueiredo I, NavaRodrigues D, Smith A, Leux C, Garcia-Murillas I, et al. Serial next-generation sequencing of circulating cell-free DNA evaluating tumor clone response to molecularly targeted drug administration. Clin Cancer Res. 2015; 21:4586-4596. https://doi.org/10.1158/1078-0432.CCR$15-0584$. 